\title{
The Influence of Feed Particle Size on Pyrolysis Characteristics of Lignite
}

\author{
Xiaonan Zhao ${ }^{1 \mathrm{a}}$, Erqiang $\mathrm{Su}^{1 \mathrm{~b}}$, Qicheng Wang ${ }^{1 \mathrm{c}}$, and Daohong $\mathrm{Wu}^{1 \mathrm{~d}}$ \\ ${ }^{1}$ Beijing Shenwu Environment \& Energy Technology Co., Ltd., Beijing, China 102200 \\ azhaonan354@163.com, bseq407@163.com, cwangqicheng@shenwu.com, \\ wudaohong@shenwu.com
}

\begin{abstract}
Keywords: Lignite; Particle size; Pyrolysis time; Pyrolysis energy consumption; Dust content. Abstract. The influence of feed particle size on the pyrolysis products, pyrolysis time, pyrolysis energy consumption and the percentage of dust content in volatile product was investigated in the fixed bed reactor. The results showed that with feed particle size increase, pyrolysis time and the percentage of dust content in volatile product were decreased, and pyrolysis energy consumption was changed a little. When the particle size was in the range of $20-30 \mathrm{~mm}$, the escape resistance of volatile product in lignite pyrolysis process was smaller, secondary reaction and carbon deposition probability were smaller, and the pyrolysis was more suitable.
\end{abstract}

\section{Introduction}

The typical characteristic of fossil energy in China is rich in coal, short of oil and gas. In the proven fossil energy reserves, coal was accounted for $94.3 \%$, oil and gas were accounted for $5.7 \%$. The low rank coal accounts for about $50 \%$ of the coal reserve resources. The low rank coal could be transferred into char, tar and gas through pyrolysis. Therefore, developing modern coal chemical industry which is helpful to realize the clean and efficient utilization of coal is one of the most important ways to deal with the energy crisis in China. ${ }^{[1,2]}$

In coal pyrolysis, especially lump coal pyrolysis process, the feed particle size is one of the most important factor which affects the heat transfer rate in the pyrolysis process and the property of pyrolysis products. If the feed particle size is too big, the degree of coal pyrolysis will be inadequate, and the first volatile product remains in the lump coal for a long time, which would cause the secondary pyrolysis and the lower tar production yield; while if the particle size is much smaller, the void ratio of coal is smaller, the percentage of dust content in volatile product will be increased and volatile product discharge from coal will be difficult. ${ }^{[3-5]}$ Therefore, it is particularly important for choosing appropriate particle size of coal before pyrolysis.

In this paper, the influence of the feed particle size on the pyrolysis products, pyrolysis time, pyrolysis energy consumption and the percentage of dust content in volatile product was investigated in the fixed bed reactor.

\section{Experimental}

This low temperature pyrolysis experiment device was shown in Fig.1, and its processing capacity was $3 \mathrm{~kg}$ per time. The device was mainly composed of reaction system, oil and water condensation system, pyrolysis gas measurement and instrument control system. The process of this experiment was as follows: coal sample was fed into the fixed bed reactor after being crushed and screened. recorded the thickness of material layer, purged the reactor using nitrogen, set the pyrolysis temperature, heating rate and residence time, recorded the initial value of wet-type flowmeter, and then started the experiment. Volatile product was condensed by condensing system, oil/water mixture into the liquid storage tank, and pyrolysis gas discharged from the condenser into the wet-type flowmeter. After the experiment was finished, shut off the heating furnace, recorded wet-type 
flowmeter date. The oil/water mixture was separated. Weighted the char after the reactor temperature was lower than $50^{\circ} \mathrm{C}$

BEILUTIAN lignite was chose as the coal samples for this experiment whose particle size fraction was $0-50 \mathrm{~mm}$. The influence of the feed particle size on the pyrolysis products, pyrolysis time, pyrolysis energy consumption and the percentage of dust content in volatile product was investigated in the fixed bed reactor. The total water of coal sample was $25.90 \%$; air dry basis of volatile was $37.11 \%$. The results of coal quality analysis for raw coal was shown that it can be improved its use efficiency by pyrolysis.

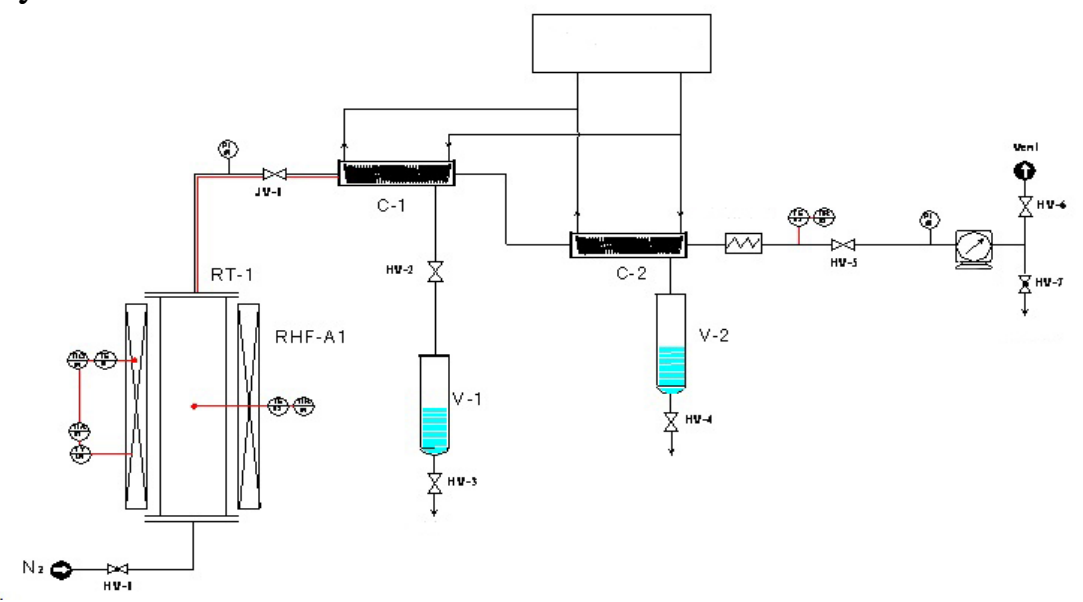

Fig.1 pyrolysis process diagram

\section{Results and discussion}

The influence of particle size on density of void ratio. The particle size of coal is one of the most important factors that affect the void ratio and will further affect the pyrolisis characteristics of coal. The results of apparent density, bulk density and void ratio measured for the coal samples with different particle size fraction were shown that: the apparent density of the coal sample was about $1260 \mathrm{~kg} / \mathrm{m}^{3}$, bulk density was in the range of $460-600 \mathrm{~kg} / \mathrm{m}^{3}$, and void ratio was in the range of 0.52-0.64. With the particle size of coal sample increase, the value of bulk density was decreased, the value of void ratio was increased gradually, and the value of apparent density is almost the same.

The influence of particle size on pyrolysis products. The particle size of coal sample can influence the heating rate and the volatiles derivation from the coal internal. The yield of the volatile product and char under the conditions of different feed particle size was shown in Fig. 2. The volatile (tar, gas, pyrolysis water) product yield was increased with the particle size increase in the range of $0-30 \mathrm{~mm}$, while the yield of volatile product was decreased with particle size increase in the range of 30-50mm; the char product yield with the change of particle size was just the opposite with volatile product, which was decreased with the particle size increase in the range of $0-30 \mathrm{~mm}$ and was increased with the particle size increases in the range of $30-50 \mathrm{~mm}$.

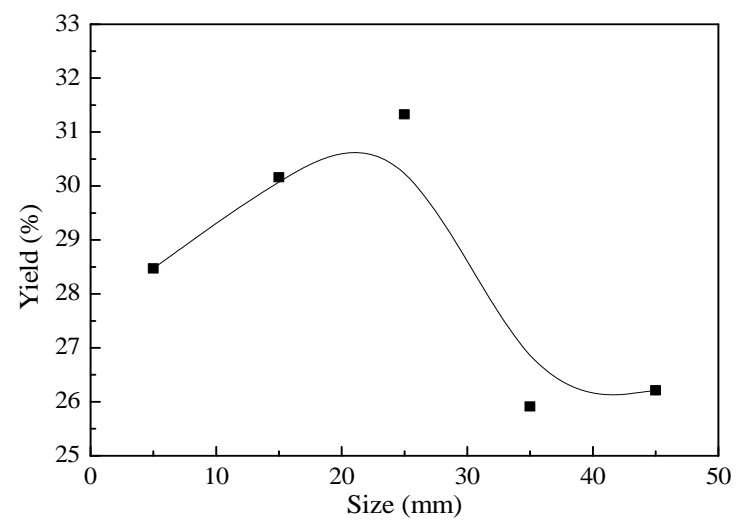

(a) Volatile product

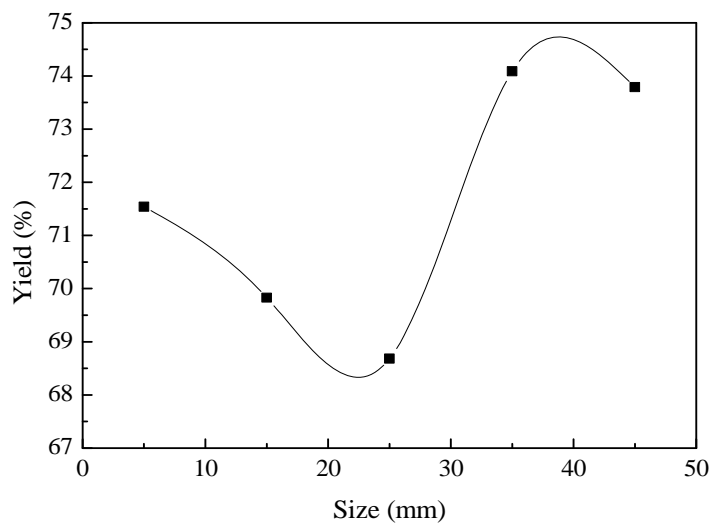

(b) Char

Fig.2 The influence of particle size of coal on productivity of pyrolysis product 
Cause analysis: within the particle size in the range of $0-30 \mathrm{~mm}$, the void ratio of coal samples (that is, it showed the resistance between the particles) was played an important role on affecting the yield of pyrolysis products. With the void ratio increase, the resistances of volatiles escape from among the particles were decreased, and the secondary reaction and carbon deposition probability was decreased. While with the particle size in the range of $30-50 \mathrm{~mm}$, the particle size was played an important role on affecting the yield of pyrolysis products. With the particle size increase, the resistances of volatiles escape from inside the particles were increased, and the secondary reaction and the possibility of carbon deposit were also increased. As a result, Lump coal in the size of $20-30 \mathrm{~mm}$ was suitable to pyrolysis, the escape resistance of volatiles in coal pyrolysis process was smaller and secondary reaction and carbon deposition probability was also smaller.

The influence of particle size on pyrolysis time. The influence of the particle size of coal on pyrolysis time was greater; the pyrolysis time under different particle size of coal was shown in Fig.3. When the particle size of coal was $0-10 \mathrm{~mm}$ pyrolysis time was $197 \mathrm{~min}$ and when the particle size was 20-30mm pyrolysis time was174min; with the coal particle size increase, pyrolysis time was gradually reduced.

Cause analysis: heat transfer rate in the pyrolysis process was decided by the particle size. With the particle size increase, the pyrolysis rate was increased, the void ratio among the particles were increased, and the heat transfer resistances between particles were decreased, therefore, the pyrolysis time was shortened; while with the particle size increase, the heat transfer resistance inside the particles was increased, and coal can't be fully pyrolyzed.

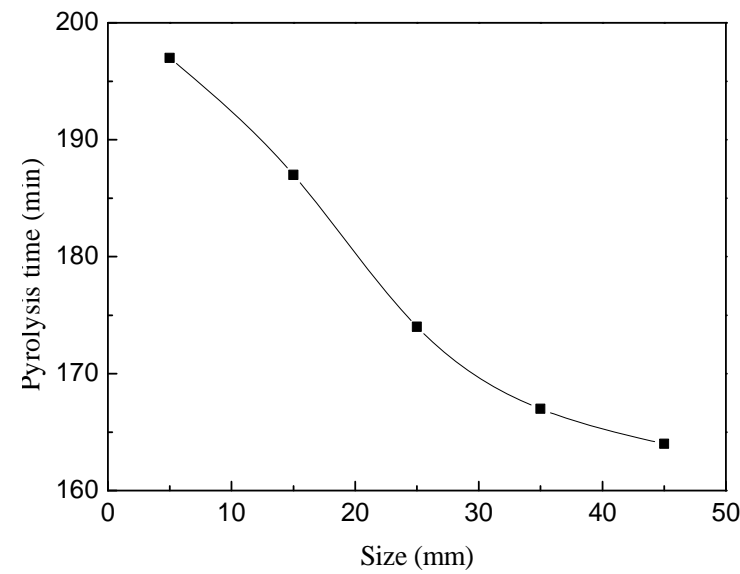

Fig.3 The influence of particle size of coal on pyrolysis time

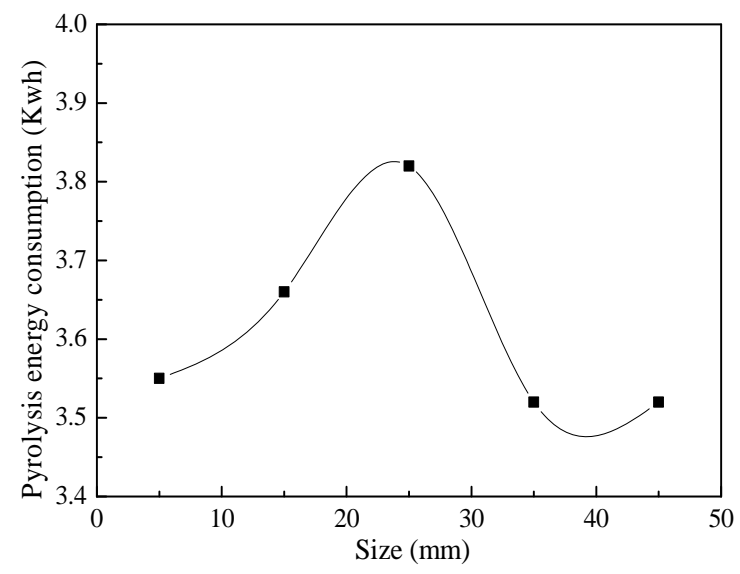

Fig.4 The influence of particle size of coal on pyrolysis energy consumption

The influence of particle size on pyrolysis energy consumption. The pyrolysis energy consumption under different particle size of coal was shown in Fig.4. When the particle size was in the range of $0-10 \mathrm{~mm}$ pyrolysis energy consumption was $3.55 \mathrm{KWh}$; and when the grain size was in the range of $30-40 \mathrm{~mm}$ pyrolysis energy consumption was $3.49 \mathrm{KWh}$; with the particle size increase, pyrolysis energy consumption was changed a little.

Cause analysis: the energy consumption of coal pyrolysis included the absorption heat in the coal reaction process and the absorption heat in the temperature-rise period of coal. The absorption heat in the coal temperature-rise period was decided by the specific heat capacity of coal, and the absorption heat in the coal reaction process was decided by the specific enthalpy of coal pyrolysis reaction. The specific heat capacity of coal and the specific enthalpy of coal pyrolysis reaction were mainly determined by the physical and chemical properties of coal, and coal particle size has little to do, therefore, the coal particle size had little effect on pyrolysis energy consumption.

The influence of particle size on the percentage of dust content in volatile product. The percentage of dust content in the volatile product (tar and gas) under different particle size of lignite after pyralysis was shown in Fig. 5. The percentage of dust content in tar and gas were both decreased 
with the particle size increase, and the percentage of dust content in tar was greater than the percentage of dust content in gas. The range of coal particle size increased from $0-10 \mathrm{~mm}$ to $40-50 \mathrm{~mm}$, the percentage of dust content in the gas was decreased from $0.022 \mathrm{mg} / \mathrm{L}$ to $0.0113 \mathrm{mg} / \mathrm{L}$. It can be seen that with the coal particle size decrease, the percentage of dust content which was produced in the pyrolysis process was increased, and it was more likely to be brought out by volatile product. In addition, due to the viscosity of oil is greater than the water and gas, dust was more easy to combine with tar and not easy to be separated. So, the percentage of dust content in tar was greater than the percentage of dust content in gas in the same range of feed particle size.

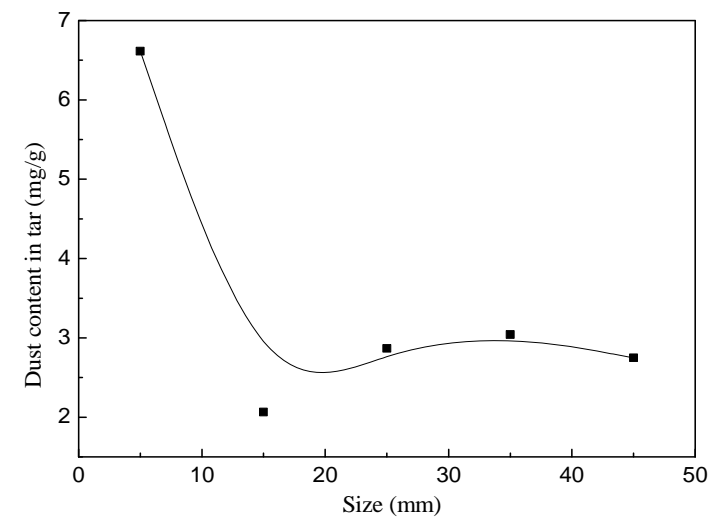

(a) The percentage of dust content in tar

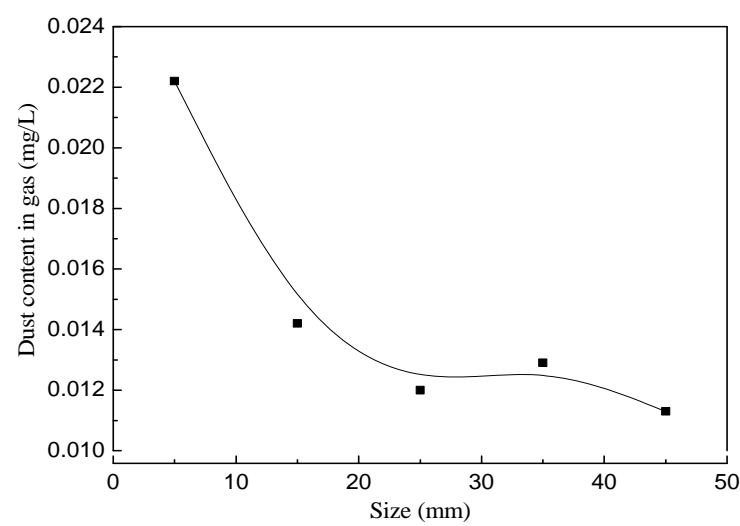

(b) The percentage of dust content in gas

Fig.5 The influence of particle size of coal on the percentage of dust content in volatile product

\section{Conclusions}

In this paper, the density and void ratio of lignite, pyrolysis products, pyrolysis time, pyrolysis energy consumption and dust content in volatile product of coal under different particle size were investigated. The experimental conclusions as follows:

1) With particle size of coal increase, the bulk density was decreased gradually, the void ratio was increased gradually, and the apparent density was almost unchanged.

2) With particle size of coal increase, the yield of volatile product (tar, gas, pyrolysis water) was increased in the range of $0-30 \mathrm{~mm}$, and the yield of volatile product was decreased in the range of $30-50 \mathrm{~mm}$; while the change of char yield with particle size was opposite to the volatile product.

3) With particle size of coal increase, the pyrolysis time was decreased, and the energy consumption of pyrolysis was changed a little.

4) With particle size of coal increase, the dust content tar and gas is decreased, and the percentage of dust content in tar was higher than that in gas.

\section{References}

[1] LI Hong-yue. Study of the relationship between energy consumption and economic growth of China[J]. Inquiry Into Economic Issues,2012,(1): 14-19.(In Chinese)

[2] WANG Jian-guo,ZHAO Xiao-hong. Demonstration of key technologies for clean and efficient utilization of low-rank coal[J]. Bulletin of Chinese Academy of Sciences,2012, 27(3):382-388. (In Chinese)

[3] WANG Jian-guo,ZHAO Xiao-hong. Demonstration of key technologies for clean and efficient utilization of low-rank coal[J]. Bulletin of Chinese Academy of Sciences,2012, 27(3):382-388. (In Chinese)

[4] XUN Hua,HAN Jian-chun,LIU Wei. Particle size and heating rate on the low calorific value coal pyrolysis effect research[J]. Power System Engineering, 2012,28(1):13-15. (In Chinese)

[5] LV Tai,ZHANG Cui-zhen, WU Chao. Study on the effect of coal diameter and heating rate on the coal pyrolysis[J]. Coal Conversion,2005, 28(1):17-20. (In Chinese) 